\title{
Bisphosphine-Catalyzed Mixed Double-Michael Reactions: Asymmetric Synthesis of Oxazolidines, Thiazolidines, and Pyrrolidines
}

\author{
Vardhineedi Sriramurthy, Gregg A. Barcan, and Ohyun Kwon ${ }^{\star}$ \\ Department of Chemistry and Biochemistry, University of California, Los Angeles, California \\ 90095-1569
}

\section{Abstract}

Bisphosphine-catalyzed mixed double-Michael reactions have been developed to afford $\beta$-amino carbonyl derivatives of oxazolidines, thiozolidines, and pyrrolidines in excellent yields and with high diastereoselectivities. Efficient reactions between amino acid-derived pronucleophiles, e.g., $\beta$-amino alcohols, $\beta$-amino thiols, and $\gamma$-amino diesters, as Michael donors and electron-deficient acetylenes, e.g., propiolates, acetylacetylene, and tosylacetylene, as Michael acceptors provided access to azolidines containing both diversity of substituents and asymmetry. This methodology - the first examples of mixed double-Michael reactions of acetylenes-is operationally simple and involves mild conditions. Mechanistically, it constitutes a rare example of the anchimeric assistance of bisphosphines in organocatalysis.

Five-membered nitrogen atom-containing heterocycles are structural components of many natural products and pharmaceuticals; ${ }^{1}$ in addition, many of them—-for example, enantiopure azolidine derivatives - have been employed as synthetic intermediates, auxiliaries, ligands, and catalysts for asymmetric synthesis. ${ }^{2}$ Consequently, there is a high demand for new methods for the efficient construction of optically active azolidine derivatives. ${ }^{3}$ As part of a program aimed at developing phosphine-mediated annulation reactions, ${ }^{4}$ we sought a novel route toward highly substituted and functionalized five-membered-ring nitrogen atom-containing heterocycles. In light of recent reports on the phosphine-catalyzed conjugate additions of electron-deficient olefins and acetylenes with alcohols, ${ }^{5}$ herein we report a bisphosphinecatalyzed mixed double-Michael process ${ }^{6}$ that generates azolidines (2; eq 1). Use of amino acid-derived pronucleophiles (1) as Michael donors and electron-deficient acetylenes as Michael acceptors provides efficient access to azolidines containing both diversity and asymmetry.

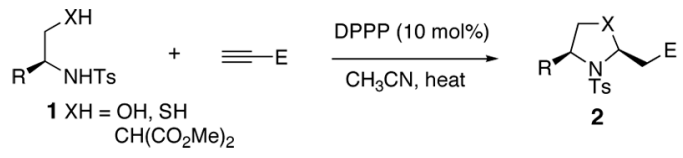

Our initial evaluation of the proposed double-Michael addition began with the reaction between amino alcohol 1a and methyl propiolate (Table 1). Employing $\mathrm{PPh}_{3}$ as the catalyst gave the desired double-Michael adduct $2 \mathbf{a}$ in $35 \%$ yield in addition to a $40 \%$ yield of the mono-Michael adduct $3 \mathbf{a}$ (entry 1). ${ }^{7}$ Use of $\mathrm{Ph}_{2} \mathrm{PEt}$ led to a moderate improvement in the yield of the oxazolidine product $2 \mathbf{a}$ (entry 2 ), but none was formed from the reaction catalyzed by $\mathrm{Me}_{3} \mathrm{P}$ 
(entry 3). ${ }^{8}$ In contrast, diphenylphosphinopropane (DPPP) catalysis increased the yield of the desired double-Michael adduct $\mathbf{2 a}$ to $71 \%$ (entry 4). ${ }^{9}$ Further increases in the yield and reaction rate were achieved when performing the reaction in a more polar solvent, $\mathrm{CH}_{3} \mathrm{CN}$ (entry 5). Based on the encouraging results we obtained with DPPP as the catalyst, we also tested the applicability of the homologous bisphosphines diphenylphosphinomethane (DPPM), diphenylphosphinoethane (DPPE), diphenylphosphinobutane (DPPB), and diphenylphosphinopentane (DPPPent). The appreciably poorer yield (37\%) of the DPPMmediated reaction, relative to those of the other bisphosphines (entries 6-9), provides a critical clue regarding the reaction mechanism (vide infra).

Scheme 1 presents a plausible mechanism for the dependence of the reaction on both the bidentate nature of the phosphine catalyst and the tether length between the two phosphine moieties. The reaction is triggered by the conjugate addition of the phosphine to the electrondeficient acetylene. The resulting vinyl anion $\mathbf{4}$ deprotonates the pronucleophile $\mathbf{1}$, which facilitates the first conjugate addition to form intermediate $6.5 b, 10$ Upon $\beta$-elimination of the phosphine, the mono-Michael product $\mathbf{3}$ is formed. The presence of an additional phosphine moiety at the optimal distance, as in DPPP, provides additional stabilization to the intermediate phosphonium ions 6 and 7. The latter undergoes $\mathrm{S}_{\mathrm{N}} 2$ displacement to produce the cyclized product $2 .{ }^{11}$ In the absence of anchimeric assistance, as in the case of the monodentate phosphines, the decreased stability of the phosphonium ion led to an unfavorable equilibrium for the formation of $\mathbf{6}$ from 3 . $^{12}$ The relatively short tether of DPPM prohibits the orbital overlap required for anchimeric assistance because of geometrical constraints. The other phosphines for which intramolecular stabilization was possible, namely DPPE, DPPB, and DPPPent, gave results similar to those obtained using DPPP. Note that intramolecular stabilization of phosphonium ions by nitrogen atoms has precedent in the literature. ${ }^{13}$

With the optimal reaction conditions in hand, i.e., DPPP as catalyst and $\mathrm{CH}_{3} \mathrm{CN}$ as solvent, we next explored the scope of the double-Michael reaction using a variety of amino acid-derived pronucleophiles and electron-deficient acetylenes (Table 2). The formation of oxazolidines from $\beta$-amino alcohols and methyl propiolate proceeded smoothly, with high yields and diastereoselectivities (entries 1 and 4). The Michael acceptors acetylacetylene and tosylacetylene also gave good results (entries 2 and 3). This methodology works well for the syntheses of thiazolidines from $\beta$-amino thiols (entries 5-7). ${ }^{14}$ All of the substrates provided similarly high yields and diastereoselectivities for the formation of thiazolidines. 15

We further tested the generality of our reaction by using carbonucleophiles (entries 8-10) for the preparation of pyrrolidine derivatives, which are ubiquitous in natural products of pharmacological interest. ${ }^{16}$ Under the optimized conditions, we generated the pyrrolidines $\mathbf{2 h}$ and $\mathbf{2} \mathbf{i}$ from the valine-derived $\gamma$-amino malonate $\mathbf{1 h}$ (entries 8 and 9 , respectively). ${ }^{17}$ Employing the cyclic $\boldsymbol{\gamma}$-amino diester $\mathbf{1} \mathbf{j}$ furnished the octahydroindole derivative $\mathbf{2} \mathbf{j}$ as a single diastereoisomer in good yield (entry 10). Octahydroindoles, which are present in a large number of natural products, are often challenging synthetic targets. 18

In summary, we have developed a remarkably simple protocol for the synthesis of oxazolidines, thiozolidines, pyrrolidines, and octahydroindoles. This mixed double-Michael process operates best under bisphosphine catalysis to provide $\beta$-amino carbonyl derivatives of azolidines ${ }^{19}$ in excellent yields and with high diastereoselectivities. Presumably, the use of bis(diphenylphosphine) derivatives allows intramolecular stabilization of the phosphonium ion intermediates. We are currently exploring the development of an enantioselective version of this ring-forming process from achiral starting materials and its application to the synthesis of selected drug candidates. 


\section{Supplementary Material}

Refer to Web version on PubMed Central for supplementary material.

\section{Acknowledgment}

This study was funded by the NIH (R01GM071779). We thank Dr. Saeed Khan for performing the crystallographic analyses. O.K. thanks Drs. Patrick J. Walsh and Chulbom Lee for helpful discussions.

\section{References}

1. Butler MS. J. Nat. Prod 2004;67:2141. [PubMed: 15620274]

2. Jacobsen, EN.; Pfaltz, A.; Yamamoto, H., editors. Comprehensive Asymmetric Catalysis I-III. Berlin: Springer; 1999. Ojima, I., editor. Asymmetric Synthesis. 2nd ed. VCH: New York: VCH; 2000. (c) Fache F, Schultz E, Tommasino ML, Lemaire M. Chem. Rev 2000;100:2159. [PubMed: 11749286] Paquette, LA., editor. Chiral Reagents for Asymmetric Synthesis. 2003. Chichester: Wiley; (e) Seayad J, List B. Org. Biomol. Chem 2005;3:719. [PubMed: 15731852]

3. Katritzky, AR., editor. "Heterocycles," a special issue of Chem. Rev. 104. 2004. p. 2125-2812.

4. (a) Zhu X-F, Henry CE, Kwon O. J. Am. Chem. Soc 2007;129:6722. [PubMed: 17488018] (b) Castellano S, Fiji HDG, Kinderman SS, Watanabe M, de Leon P, Tamanoi F, Kwon O. J. Am. Chem. Soc 2007;129:5843. [PubMed: 17439124] (c) Mercier E, Fonovic B, Henry CE, Kwon O, Dudding T. Tetrahedron Lett 2007;48:3617. (d) Dudding T, Kwon O, Mercier E. Org. Lett 2006;8:3643. [PubMed: 16898781] (e) Tran YS, Kwon O. Org. Lett 2005;7:4289. [PubMed: 16146409] (f) Zhu X-F, Henry CE, Wang J, Dudding T, Kwon O. Org. Lett 2005;7:1387. [PubMed: 15787513] (g) Zhu X-F, Schaffner A-P, Li RC, Kwon O. Org. Lett 2005;7:2977. [PubMed: 15987184] (h) Zhu X-F, Henry CE, Kwon O. Tetrahedron 2005;61:6276. (i) Zhu X-F, Lan J, Kwon O. J. Am. Chem. Soc 2003;125:4716. [PubMed: 12696883]

5. (a) Stewart IC, Bergman RG, Toste FD. J. Am. Chem. Soc 2003;125:8696. [PubMed: 12862443] (b) Inanaga J, Baba Y, Hanamoto T. Chem. Lett 1993;2:241.

6. Intramolecular double-Michael reactions of acetylenes. Double-carbo-Michael(a) Grossman RB. Synlett 2001:13.Double-thia-Michael (b) Kuroda H, Tomita I, Endo T. Synth. Commun 1996;26:1539.Double-oxa-Michael (c) Ariza X, Costa AM, Faja M, Pineda O, Vilarrasa J. Org. Lett 2000;2:2809. [PubMed: 10964371] (d) Forsyth CJ, Hao J, Aiguade J. Angew. Chem., Int. Ed 2001;40:3663.Double-aza-Michael (e) Diez-Barra E, Guerra J, Hornillos V, Merino S, Tejeda J. Tetrahedron Lett 2004;45:6937.

7. The structures of $\mathbf{2} \mathbf{a}$ and $\mathbf{3 a}$ were confirmed through X-ray crystallographic analysis. See the Supporting Information for details.

8. Other bases known to facilitate Michael addition of alcohols to alkynes, such as $\mathrm{K}_{2} \mathrm{CO}_{3}$ and morpholine, did not provide any cyclized product.Eaton PE, Stubbs CE. J. Am. Chem. Soc 1967;89:5722.Lee E, Tae JS, Lee C, Park CM. Tetrahedron Lett 1993;34:4831.

9. For examples of the use of bisphosphines in organocatalysis, see:Trost BM, Li C-J. J. Am. Chem. Soc 1994;116:10819.(b) Trost BM, Dake GR. J. Am. Chem. Soc 1997;119:7595. (c) Kamijo S, Kanazawa C, Yamamoto Y. Tetrahedron Lett 2005;46:2563. (d) Silva F, Sawicki M, Gouverneur V. Org. Lett 2006;8:5417. [PubMed: 17078732]

10. Alternatively, the deprotonated nucleophile can add to the acetylene to form a vinyl anion, which will deprotonate the pronucleophile and form 3 . In this scenario, the phosphine is an initiator for the actual catalytic cycle. See:Grossman RB, Comesse S, Rasne RM, Hattori K, Delong MN. J. Org. Chem 2003;68:871. [PubMed: 12558409] and references therein

11. Alternatively, one can invoke a mechanism where intermediate 6 functions as a base to deprotonate 3, which subsequently undergoes intramolecular Michael addition. The resulting enolate deprotonates another molecule of $\mathbf{3}$ to reiterate the productive cycle. Ion paring between the protonated $\mathbf{6}$ and deprotonated $\mathbf{3}$ (and the following intermediates) has been proposed previously; see: (a) ref ${ }^{5 a}$.White DA, Baizer MM. Tetrahedron Lett 1973;14:3579.

12. The $\beta$-alkoxy acrylate intermediate 3a smoothly converted to the cyclized product 2a in $94 \%$ yield when treated with DPPP. 
13. Although hexamethylphosphorous triamide (HMPT) did not facilitate any Michael reaction, Verkade's proazaphosphatrane $(10 \mathrm{~mol} \%)$ provided the desired cyclized product in $42 \%$ yield, indicating that other donators of electron lone pairs can provide similar anchimeric assistance.Kisanga PB, Ilankumaran P, Fetterly BM, Verkade JG. J. Org. Chem 2002;67:3555. [PubMed: 12027665]Verkade JG, Kisanga PB. Aldrichim. Acta 2004;37:3.

14. Anderson JC, Cubbon R, Harding M, James DS. Tetrahedron: Asymmetry 1998;9:3461.

15. 1,2-Diamine pronucleophiles are known to provide piperazines under phosphine catalysis; see:Lu C, Lu X. Org. Lett 2002;4:4677. [PubMed: 12489959]

16. (a) O'Hagan D. Nat. Prod. Rep 2000;17:435. [PubMed: 11072891] (b) Daly JW, Spande TF, Garraffo HM. J. Nat. Prod 2005;68:1556. [PubMed: 16252926]

17. Mao H, Joly GJ, Peeters K, Hoornaert GJ, Compernolle F. Tetrahedron 2001;57:6995.

18. Kobayashi, J.; Morita, H. The Alkaloids. Cordell, GA., editor. Vol. 60. New York: Academic; 2003. p. 165 (b) Hanessian S, Tremblay M, Petersen JFW. J. Am. Chem. Soc 2004;126:6064. [PubMed: 15137772] (c) Aron ZD, Overman LE. Org. Lett 2005;7:913. [PubMed: 15727473]

19. Fustero S, Jimenez D, Sanchez-Rosello M, del Pozo C. J. Am. Chem. Soc 2007;129:6700. [PubMed: 17480078] 

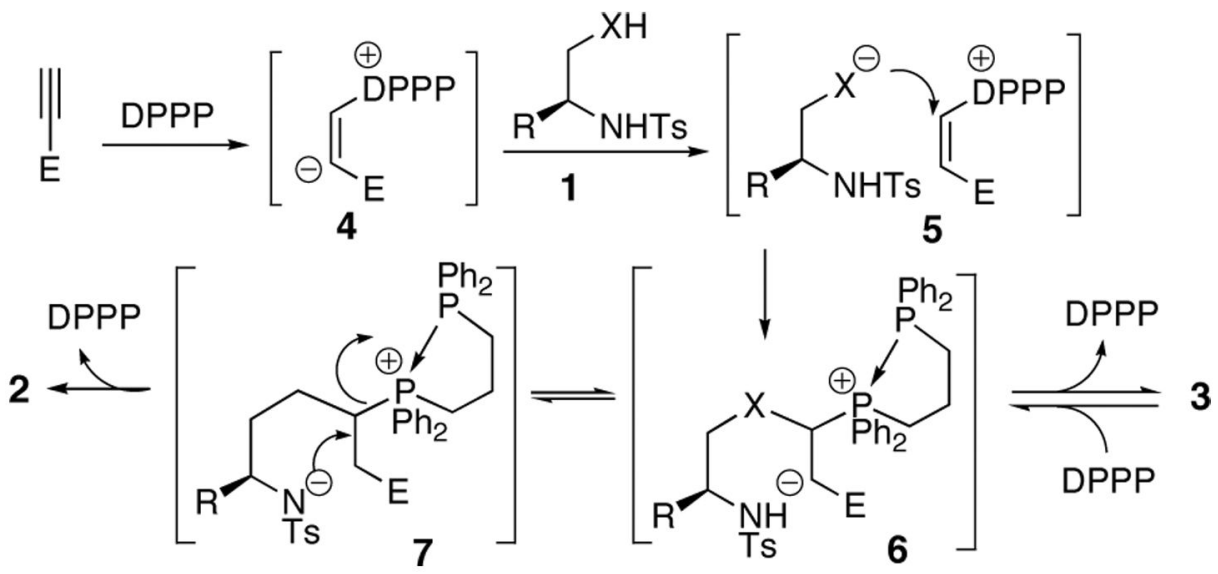

Scheme 1.

Proposed mechanism for the formation of $\mathbf{2}$ 
Table 1

Evaluation of Catalysts for Double-Michael Additions ${ }^{a}$

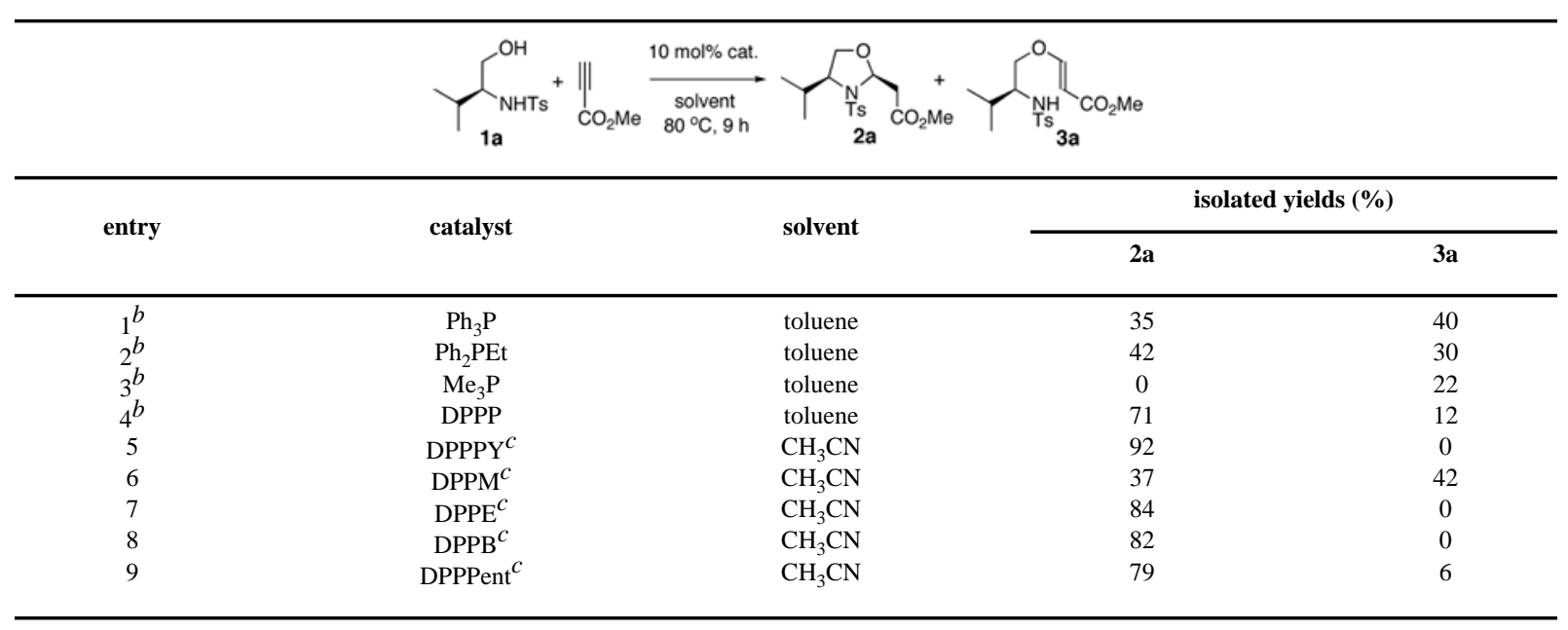

${ }^{a}$ All reactions were performed using $1 \mathrm{mmol}$ of $\mathbf{1 a}, 1.1 \mathrm{mmol}$ of methylpropiolate, and $10 \mathrm{~mol} \%$ of the catalyst.

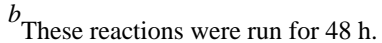

${ }^{c}$ DPPM, DPPE, DPPP, DPPB, and DPPPent are acronyms for diphenylphosphinomethane, -ethane, -propane, -butane, and -pentane, respectively. 


\section{Table 2}

Syntheses of Various Azolidines ${ }^{a}$

\begin{tabular}{|c|c|c|c|}
\hline entry & substrate & product & yield $\%($ cis:trans $) b c$ \\
\hline 1 & & & $92(96: 4)$ \\
\hline 2 & 1a & & $92(94: 6)$ \\
\hline 3 & 1a & & $87(97: 3)$ \\
\hline 4 & & & $91(95: 5)$ \\
\hline 5 & & & $93(95: 5)$ \\
\hline 6 & $1 e$ & & 89 (96:4) \\
\hline 7 & & & $88(96: 4)$ \\
\hline 8 & & & $82(94: 6)$ \\
\hline 9 & $1 \mathrm{~h}$ & & $91(95: 5)$ \\
\hline 10 & $\mathrm{CO}_{2} \mathrm{M}$ & & $80(100: 0)$ \\
\hline
\end{tabular}

${ }^{a}$ All reactions were performed using $1 \mathrm{mmol}$ of the substrate, 1.1 equiv of the corresponding acetylene, and $10 \mathrm{~mol} \%$ of DPPP in $\mathrm{CH}_{3} \mathrm{CN}$ at $80{ }^{\circ} \mathrm{C}$ for 9 h.

${ }^{b}$ Isolated yields after chromatographic purification.

${ }^{c}$ Determined through ${ }^{1} \mathrm{H}$ NMR spectroscopic analysis. 